\title{
Guidelines for Increasing Female Authorship of GI Society Guidelines
}

\author{
Richa Shukla ${ }^{1}$ Sharmila Anandasabapathy ${ }^{1,2}$
}

Published online: 2 April 2020

(c) Springer Science+Business Media, LLC, part of Springer Nature 2020

It has been over 180 years since Elizabeth Blackwell became the first woman to obtain a medical degree in the USA, paving the way for other women to enter the field. Today, women account for $35.4 \%$ of all physicians and $17.6 \%$ of gastroenterologists [1]. Despite this, there remains a dearth of women in leadership positions in national societies and in the highest rungs of academia. For example, in 2015 women constituted $<20 \%$ of GI fellowship program directors and $<10 \%$ of section/division chiefs [2,3]. While there has been some positive change with a recent increase in women in executive leadership of GI societies (AGA, AASLD, ACG, ASGE), this has not translated into publication leadership. Indeed, the engaging and provocative study by Bushyhead et al. published in this month's Digestive Diseases and Sciences examines this particular disparity in greater detail: Are there gender differences in female authorship and leadership of technical reviews and society guidelines? [4].

In order to demonstrate that an "authorship gender gap" of national society publications, the authors retrospectively evaluated 90 technical reviews and guidelines between 2007 and 2019 from AASLD, ACG, and AGA. The authors determined the ratio of female authors to the total number of authors. They also evaluated trends in these ratios over three periods of time. Among the 90 examined publications, only $21 \%$ had female authorship. When looking at temporal trends, the authors of the study found that although the number of published technical reviews and guidelines increased over time, female authorship remained consistently below that of men. In terms of society-specific trends, the authors discovered that female authorship did increase from 21 to $35 \%$ in AASLD publications from 2007-2010 to 2015-2019;

Sharmila Anandasabapathy

anandasa@bcm.edu

Richa Shukla

Richa.Shukla@bcm.edu

1 Section of Gastroenterology and Hepatology, Baylor College of Medicine, Houston, USA

2 Baylor Global Health, Houston, USA female authorship in ACG publications remained stable and actually declined among published AGA guidelines. Lastly, only $18 \%$ of first authors were female in all of the examined publications.

To explain these disparities, the authors pointed out that women still represent a minority of practicing gastroenterologists in the USA, though this does not explain the overall increase in female authorship of original research over a similar period of time. Though there is no obvious explanation for the ongoing disparity between males and females in the authorship of society reviews and guidelines, the authors of this study speculate there may be an implicit bias toward males as experts or leaders. Similar trends exist across other medical specialties and may have broader implications for the promotion of women to senior positions, and the visibility of women in their respective fields. If men are perceived as being content or thought leaders, they are more likely to ascend the ranks of academia, society leadership, thereby perpetuating the status quo.

The study by Bushyhead et al. is timely in light of other recent research addressing gender differences in publication. A recent article from Lerchenmueller et al. [5] showed that female researchers do not promote their work with the same degree of "positivity" (i.e., using words like "novel," "unique," and "unprecedented to describe their research) as their male counterparts. This pattern, the authors suggest, reflects a lack of self-promotion that leads to less prominence in research authorship. Indeed, given the importance of publications and authorship in the promotion process, the above research is cause for concern, suggesting that a more structured approach should be used to address the myriad issues involved. Indeed, some overt barriers that may exist include a lack of appropriate mentorship and/or sponsors combined with competing outside obligations and the need for work-life balance-all factors that may impact advancement. That said, more insidious forces may be at play: Women are more likely to experience a phenomenon known as "impostor syndrome" - a feeling that they are successful "by accident" or through hard work but not due to inherent qualification and intelligence [6]. As a result, women are less 
likely to promote themselves and often (mistakenly) believe that others will recognize the quality of their work without them highlighting their successes [7].

What can be done? The solution is complex, requiring a combination of education and awareness to address these deep and subtle issues. Nevertheless, there also has to be a more structured and conscious attempt to actively include expert women in the creation of high-impact guidelines.

Some ideas:

- National Societies: Efforts should be made to promote women into leadership roles that also include authorship of highly cited publications such as clinical practice guidelines

- Journals: Editorial boards should be aware of these unconscious patterns in language and educate their reviewers, so they can flag and/or consider these differences.

- GI Divisions and Practices: GI Divisions, practice groups, and societies should maintain awareness of these gender disparities and encourage women to actively voice their career aspirations and "sponsor" women into opportunities that will allow advancement into prominent leadership roles

To overcome the existing status quo, female gastroenterologists will need to empower themselves and one another to rise to prominent positions in research and society governorship. Academic institutions and national societies will also need to set the example by supporting and, more importantly, promoting women. As things continue to move in a positive direction and more women occupy leadership positions in gastroenterology, at some point the term "female leaders" will be replaced by simply by the term "leaders."

\section{References}

1. https://www.aamc.org/data-reports/workforce/interactive-data/ active-physicians-sex-and-specialty-2017.

2. Woodward Z, Rodriguez Z, Jou JH, et al. Gender disparities in gastroenterology fellowship director positions in the United States. Gastrointest Endosc. 2017;86:595-599.

3. Pascua M, Kushner T, Woodward Z. Promoting leadership by women in gastroenterology-lessons learned and future directions. Gastroenterology. 2019;156:1548-1552.

4. Bushyhead D, Strate LL. Sex differences in authorship of major gastroenterology society guidelines and technical reviews. Dig Dis Sci. (Epub ahead of print). https://doi.org/10.1007/s10620-01906040-4.

5. Lerchenmueller MJ, Sorenson O, Jena AB. Gender differences in how scientists present the importance of their research: observational study. BMJ. 2019;16:367.

6. https://www.healio.com/gastroenterology/practice-management/ news/online/\%7B7dcef67a-c3d0-4547-a95c-c26dbecffc60\%7D/ imposter-syndrome-prevalent-among-women-in-medicine-butcan-be-overcome.

7. Babcock L, Laschever S. Women don't ask. Princeton: Princeton University Press. 2006.

Publisher's Note Springer Nature remains neutral with regard to jurisdictional claims in published maps and institutional affiliations. 